\title{
Update of Key Mechanism of Hepatic Peliosis
}

\author{
Mahmoud M Elalfy*1 and Mona G El hadidy² \\ ${ }^{1}$ Department of Forensic medicine and toxicology, faculty of veterinary medicine, mansoura university, Egypt
} ${ }^{2}$ Medical physiology faculty of medicine, mansoura university, Egypt

*Corresponding author: Mahmoud M Elalfy, Department of Forensic medicine and toxicology, faculty of veterinary medicine , mansoura university Egypt

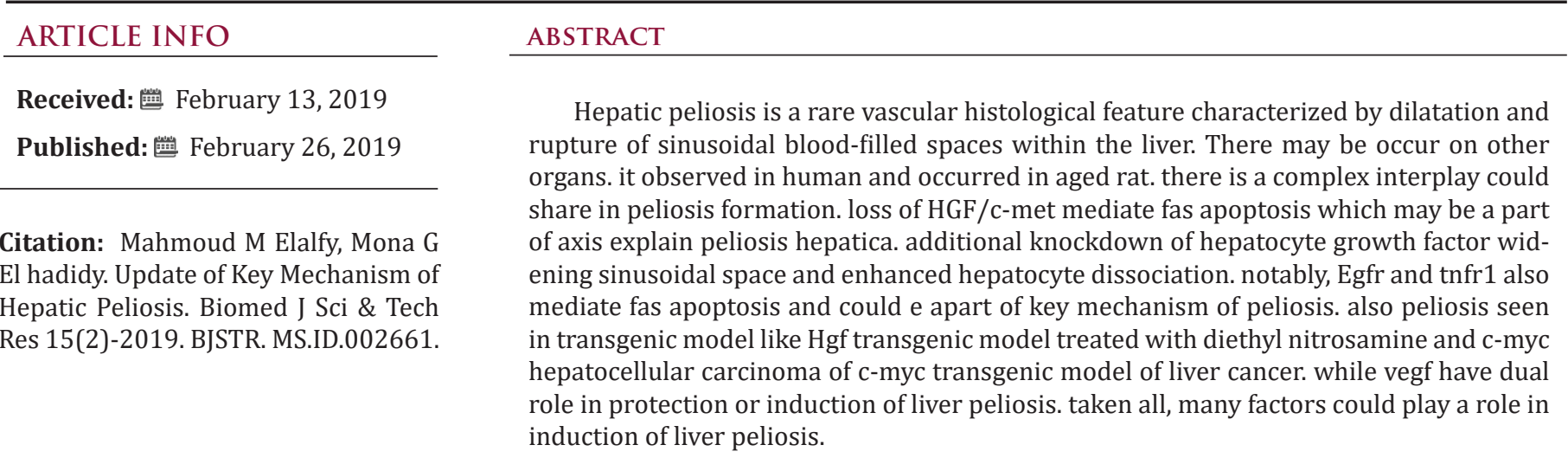

Keywords: Hepatic Peliosis; HGF/c-Met; Fas; Vegf

\section{Introduction}

Hepatic peliosis is a rare vascular condition characterized by dilatation and rupture of sinusoidal blood-filled spaces within the liver. There may be occur on other organs like spleen, bone marrow, lungs, and abdominal lymph nodes Downes et al. [1], peliosis identified by computed tomography of the abdomen of human case revealed a large well-defined lesion with heterogeneous density in the right lobe of the liver compatible with intrahepatic hemorrhage in the absence of definite extravasation (Charatcharoenwitthaya and Tanwandee, 2014). Also, spontaneous hepatic rupture, occur during pregnancy in a patient with peliosis hepatis Cimbanassi et al. [2]. peliosis hepatis, another reactive vascular lesions which radiologically similar to liver tumors, is characterized by focal or diffuse cystic blood-filled cavities mainly localized in parenchyma. Peliotic lesions show a loss of endothelial lining and replaced by perisinusoidal reticulin network. Peliosis hepatis can be caused by a wide array of factors, including chemicals, infections and drugs as recently recorded that Hepatorenal peliosis a characteristic feature of gentamox antibiotic induce toxicity in albino rats Elalfy et al. [3] and also the corticosteroid drugs induced peliosis hepatica in Systemic Lupus Erythematosus Zimmermann [4] Kimura et al. [5].

Hepatic peliosis named spongiosis hepatis is a spontaneously occurring lesion in the livers of ageing rats, appearing most often in the second year of life, with a strong predilection for male animals. The incidence of spontaneous spongiosis hepatis can reach $34 \%$ in male Fischer rats. The lesion is composed of altered sinusoidal lining cells which some authors have interpreted as hepatic stellate cells (Ito cells or fat-storing cells). The characteristic histological appearance is described by Bannasch et al. [6-8] in rats treated with carcinogens -spontaneous spongiosis hepatis is less likely to be multifocal and is less often associated with stellate cell aggregates. In contrast, electron microscope scanning revealed that hepatic stellate cells become enlarged and show apoptosis in space of dis under effect of gadolinium chloride and diethylnitrosamine induced hepatocellular carcinoma treated balb-c mice El-hadidy et al. [9]. So may be enlarged HSC responsible of widening sinusoidal space, collection of blood into small cavities and share in peliosis mechanism.

Also, Elalfy et al. [10] found that egf hepatocellular carcinoma show peliosis like appearance pathological description of peliosis by light microscopy as a centrilobular glycogen depletion and cytoplasmic foaminess, usually followed by extensive vacuolation and centrilobular congestion and hydropic single cell necrosis on mice treated with furosemide (walker). while by Electron microscopy revealed disaggregation of polyribosomes, vesiculation 
of endoplasmic reticulum, an endocytic origin for the vacuolation, and a definite sequence in the development of congestion. Walker et al. [11] the gross inspection of the peliotic lesions show the cut sections a "swiss cheese" appearance. Microscopically, there were two different types of peliosis can be identified in the liver: first type, parenchymal peliosis, composed of irregular cavities that outer lining was not be sinusoidal cells or fibrous tissue; and the second one, phlebectatic peliosis, was regular, spherical cavities protected by endothelium or fibrosis Tsokos et al. [12]. The causes of peliosis hepatica is unknown and it occasionally observed in human liver Craiget et al. [13] Many author interests to better understand explanation of liver peliosis as Munoz et al. [14] explain Peliosis Hepatis to super expression of fas legend a Complication of the Ise of Oral Contraceptives in a Patient with Myelodysplasia.

Knockdown of endothelial Fas sufficiently recapitulated the protection against hemorrhage seen with the addition of mural cells. the regulation of endothelial Fas signaling is involved in the promotion of vascular integrity by mural cells in tumors Kamei et al. [15]. Moreover, HGF is a potent angiogenic factor in vitro and in vivo Bussolino et al. [16,17], and is involved in haematopoiesis Zarnegar êt al. [18] and local regulation of fibrinolysis and coagulation Pepper et al. [19] Wojta et al. [20]. Some of HCCs in Hepatocyte growth factor transgenic mice treated with diethyl nitrosamine were accompanied peliosis-like change Horiguchi et al. [21]. The most consistent abnormality of HGF knockout mice was a loosened liver structure with enlarged sinusoidal spaces and dissociation of the parenchymal cells. The dissociated cells often showed signs of apoptosis Shiota et al. [22]. Notably, importance of TGF-beta signaling in the control of liver homeostasis and there was no peliosis seen in histology feature of c-Met (cyto-Met) and c-Myc transgenic model Amicone et al. [23].The HCCs observed in c-myc transgenic mice were either of the trabecular or of the solid histological type, varying from well differentiated to poorly differentiated tumors with cell polymorphism, atypia and areas of hemorrhagic necrosis Thorgeirsson et al. [24,25]. moreover, c-myc transgenic mice enhanced loss of c-met, receptor for hepatocyte growth factor ligand after one year aged mice Thorgeirsson et al. $[24,25]$ C-Met activation by HGF impairs Fas-triggered apoptosis of primary embryonic hepatocytes and cell survival correlates with inhibition of caspase- 8 and caspase- 3 activities. HGF treatment prevents degradation of FLIPL triggered by Fas activation.

In contrast to this, c-Met activation does not modulate FLIPL levels and its stability in untreated cells Moumen et al. (2007). Also, c-Met, a growth factor receptor tyrosine kinase a cell survival mechanism, directly binds to and sequesters the death receptor Fas in hepatocytes. This interaction prevents Fas self-aggregation and Fas ligand binding, thus inhibiting Fas activation and apoptosis Wong et al. [26]. Loss of c-Met function increased sensitivity to Fas-mediated apoptosis Gómez Quiroz et al. [27]. Fas and loss of hepatocyte growth factor, a potent hematopoietic agent, may be among the factor enhanced peliosis occurrence and complex interplay of pro-apoptotic signals and have been shown to be Fas mediated Feldmann et al. [28]. Specifically, loss of hepatocyte growth factor receptor signaling sensitizes to Fas-mediated apoptosis Gómez Quiroz et al. [27]. As Fas was strongly induced in HCC of transgenic mice that had peliosis feature histological , at least in part, by Fas mediated apoptosis of hepatic cells or epidermal growth factor receptor mediated CD95 tyrosine phosphorylation for formation of death disc, the death-inducing signaling complex Reinehr et al. [29,30]. Furthermore, EGFR ligands and TNF receptor 1 sensitizing hepatocyte apoptosis during fulminate hepatitis and for TNF signaling to mediated Fas -apoptosis Murthy et al. [31].

Finally, c-met regulating gene, Ets $1 \backslash 2$ are known regulate endothelial function and gene expression. For example, Ets1 has been shown to modulate the expression of several genes of endothelial function and angiogenesis including VEGF-R2, VEGF, and Tie2.2 However, knockdown of Ets1 is associated with defects in T-cell function, but no abnormalities in vascular development or angiogenesis. The protective agent against peliosis was recorded in rat intoxication with cadmium chloride Tzirogiannis et al. [32] by Putrescine or VEGF administration totally reversed macroscopic peliosis. Putrescine considered a major protective effect on hepatocytes, whereas the protective effect of VEGF was more significant for nonparenchymal liver cells Tzirogiannis et al. [33]. Additionally, The hepatoprotective effect of Hepatic Stimulator Substance against cadmium-induced necrosis, apoptosis, and peliosis Tzirogiannis et al. [34]. Additionally, Gene knockdown experiments have stated the potential roles played by Vascular Endothelial Growth Factor (VEGF) VEGF receptor 2 (VEGF-R2) and VEGF-R1 in new vessel formation Biscetti et al. [35-37] and have reported that PPAR alpha and PPAR gamma activation enhanced neo-angiogenesis through (VEGF) dependent key mechanism.

In contrast, excessive VEGF could be playing an etiologic role of VEGF-induced syndrome resembles peliosis hepatis, suggested by the correlation between rising serum VEGF levels and the severity of the liver pathology, a rare human condition that is happened in the setting of advanced malignancies, high-dose androgen therapy and Bartonella henselae infection Wong et al. [26]. Similarly, liver peliosis occurred in follicular lymphoma with a rise in vascular endothelial growth factor and anaemia of inflammation De la Mano et al. [38]. Also, high levels of genetically induced or tumor-produced VEGF can alter the architecture of the adult liver, enhancing a liver 'peliosis-like' phenotype that was characterized by enlarged hepatic sinusoids, blood pooling, detached sinusoidal endothelial cells and a total disruption of normal liver architecture Belteki et al., 2005 and Wong et al. [26,39,40]. on conclusion, fas and loss of hepatocyte growth factor and vascular growth factor complex may be among the factor enhanced peliosis occurrence in liver.

\section{References}

1. Downes RO, Cambridge CL, Diggiss C, Iferenta J, Sharma M (2015) A case of intra-abdominal hemorrhage secondary to peliosis hepatis. Int J Surg Case Rep 7: 47-50. 
2. Cimbanassi S, Aseni P, Mariani A, Sammartano F, Bonacina E, et al (2015) Spontaneous hepatic rupture during pregnancy in a patient with peliosis hepatis. Ann Hepatol 14(4): 553-558.

3. Elalfy M Mahmoud, Hussein A Yehia, El Hadidy G Mona, Naseif Monur (2018) Hepatorenal peliosis a characteristic features of gentamox antibiotic induce toxicity in albino rats. International Journal of Current Innovation Research 4 (2): 1029-1032.

4. Zimmermann A (2017) Tumors and Tumor-Like Lesions of the Hepatobiliary Tract. Springer pp. 1023-1037.

5. Kimura M, Aizawa A, Miyauchi S, Hasuike S, Umekita K (2019) Peliosis Hepatis Due to Corticosteroid in Systemic Lupus Erythematosus. Intern Med 2167-18.

6. Bannasch P, Bloch M, Zerban H (1981) Spongiosis hepatic: specific changes of the perisinusoidal liver cells induced in rats by N-nitrosomorpholine. Lab Invest 44(3): 252-264.

7. Bannasch P, Zerban H (1986) Pathogenesis of primary liver tumors induced by chemicals. Recent Results in Cancer Res 1-15.

8. Bannasch P, Zerban H (1997) Spongiosis hepatic and spongiotic pericytoma, rat. Digestive System pp. 104-113.

9. El hadidy Mona, Habas Amer, Menabawy Fayza, Abd elaziz Gad (2017) Role of kupffer cell in liver fibrosis and cancer in balb-c mice. Phd thesis, faculty of medicine Mansoura university p. 78-83.

10. Elalfy Mahmoud, Borlak Jürgen (2011) Prolonged phosphorylation of epidermal growth factor receptor and expression of fas legend pathway enhanced loss of hepatocyte growth factor receptor/transform growth factor beta-1 pathway in an EGF transgenic disease model of liver cancer

11. Walker RM, McElligott TF (1981) Furosemide induced hepatotoxicity. journal of pathology 135(4): 301-314.

12. Tsokos M, Erbersdobler A (2006) Peliosis of the Liver and Spleen Forensic Pathology Reviews pp. 143-158.

13. Craig JR, Peters RL and Edmondson HA (1989) Atlas of Tumor pathology, Armed Forces Institute of Pathology, Washington, DC, USA

14. Muñoz Marcela M, Rodríguez Natalie Z, Tordecilla Juan C, Ureta Ester H, Rizzardini Carlos L, et al. (2009) Peliosis Hepatis as a Complication of the Ise of Oral Contraceptives in a Patient with Myelodysplasia Rev. Chi Pediatr 80 (4): 354-360.

15. Kamei R, Tanaka HY, Kawano T, Morii C, Tanaka S, et al. (2017) Regulation of endothelial Fas expression as a mechanism of promotion of vascular integrity by mural cells in tumors. Cancer Sci 108(5): 1080-1088.

16. Bussolino F, Di Renzo MF, Ziche M, Bocchietto E, Olivero M, et al. (1992) Hepatocyte growth factor is a potent angiogenic factor which stimulates endothelial cell motility and growth. J Cell Biol 119(3): 629-641.

17. Grant DS, Kleinman HK, Goldberg ID, Bhargava MM, Nickoloff BJ, et al. (1993) Scatter factor induces blood vessel formation in vivo. Proc Nat Acad Sci USA 90(5): 1937-1941.

18. Zarnegar R, Michalopoulos GK (1995) The many faces of hepatocyte growth factor: from hepatopoiesis to hematopoiesis. J Cell Biol 129(5): 1177-1180.

19. Pepper MS, Matsumoto K, Nakamura T, Orci L, Montesano R (1992) Hepatocyte growth factor increases urokinase-type plasminogen activator ( $\mathrm{u}-\mathrm{PA}$ ) and $\mathrm{u}-\mathrm{PA}$ receptor expression in Madin-Darby canine epithelial cells. J BiolChem 267(28): 20493-20496.

20. Wojta J, Nakamura T, Fabry A, Hufnagl P, Beckmann R, et al. (1994) Hepatocyte growth factor stimulates expression of plasminogen activator inhibitor type 1 and tissue factor in HepG2 cells. Blood 84(1): 151-157.

21. Horiguchi N, Takayama H, Toyoda M, Otsuka T, Fukusato T, et al. (2002) Hepatocyte growth factor promotes hepatocarcinogenesis through c-Met autocrine activation and enhanced angiogenesis in transgenic mice treated with diethylnitrosamine. Oncogene 21(12): 1791-1799.

22. Shiota Goshi, Kawasaki Hironaka (1998) Hepatocyte growth factor in transgenic mice. Int J Exp Path 79(5): 267-277.
23. Amicone L, Terradillos O, Calvo L, Costabile B, Cicchini C, et al. (2002) Synergy between truncated c-Met (cyto-Met) and c-Myc in liver oncogenesis: importance of TGF-beta signalling in the control of liver homeostasis and transformation. Oncogene 21(9): 1335-1345.

24. Thorgeirsson SS, Santoni Rugiu E (1996) Transgenic mouse model in carcinogenesis: interaction of $\mathrm{c} \times$ myc with transforming growth factor a and hepatocyte growth factor in hepatocarcinogenesis. Br J Pharmacol 42(1): 43-52.

25. Thorgeirsson SS, Santoni Rugiu E (1997) Interaction of c-myc with transforming growth factor a and hepatocyte growth factor in hepatocarcinogenesis. Mut Res 376(1-2): 221-234.

26. Wong AK, Alfert M, Castrillon DH, Shen Q, Holash J, et al. (2001) Excessive tumor-elaborated VEGF and its neutralization define a lethal paraneoplastic syndrome. Proc Natl Acad Sci USA 98(13): 7481-7486.

27. Gómez Quiroz LE, Factor VM, Kaposi Novak P, Coulouarn C, Conner EA, et al. (2008) Hepatocyte-specific c-Met deletion disrupts redox homeostasis andsensitizes to Fas-mediated apoptosis. J Biol Chem 283(21): 14581-14589.

28. Feldmann G, Lamboley C, Moreau A, Bringuier A (1998) Fas-mediated apoptosis of hepatic cells. Biomed \& Pharmacotherapy 52(9): 378-385.

29. Reinehr R, Schliess F, Häussinger D (2003) Hyperosmolarity and CD95L trigger CD95/EGF receptor association and tyrosine phosphorylation of CD95 as prerequisites for CD95 membrane trafficking and DISC formation. FASEB J17(6): 731-733.

30. Reinehr R, Sommerfeld A, Häussinger D (2008) CD95 ligand is proliferative and antiapoptotic signal in quiescent hepatic stellate cells. Gastroenterology 134(5): 1494-506.

31. Murthy A, Defamie V, Smookler DS, Di Grapp De la Mano EP, Martín Sánchez G, et al. (2018) Peliosis hepatis associated with follicular lymphoma with a rise in vascular endothelial growth factor and anaemia of inflammation. Ecancermedicalscience 12: 882

32. A MA, Horiuchi K, et al. (2010) Ectodomain shedding of EGFR ligands and TNFR1 dictates hepatocyte apoptosis during fulminant hepatitis in mice. J Clin Invest 120(8): 2731-2744.

33. Tzirogiannis KN, Panoutsopoulos GI, Demonakou MD, Hereti RI, Alexandropoulou KN, et al. (2003) Time-course of cadmium-induced acute hepatotoxicity in the rat liver: the role of apoptosis. Arch Toxicol 77(12): 694-701

34. Tzirogiannis KN, Papadimas GK, Kondyli VG, Kourentzi KT, Demonakou MD, et al. (2006) Peliosis hepatis: microscopic and macroscopic type, time pattern, and correlation with liver cell apoptosis in a model of toxic liver injury. Dig Dis Sci 51(11): 1998-2006.

35. Tzirogiannis KN, Panoutsopoulos GI, Demonakou MD, Hereti RI, Alexandropoulou KN, et al. (2004) Effect of hepatic stimulator substance (HSS) on cadmium-induced acute hepatotoxicity in the rat liver. Dig Dis Sci 49(6): 1019-1028

36. Biscetti F, Gaetani E, Flex A, Aprahamian T, Smith RC, et al. (2008) Activation of PPAR-alpha and PPAR-gamma induces angiogenesis in vivo through a VEGF-dependent mechanism. Diabetes 57(5): 1394-1404

37. Biscetti F, Gaetani E, Flex A, Straface G, Pecorini G, et al. (2009) Peroxisome proliferator-activated receptor alpha is crucial for iloprostinduced in vivo angiogenesis and vascular endothelial growth factor upregulation. J Vasc Res 46(2): 103-108.

38. Biscetti F, Straface G, Pitocco D, Zaccardi F, Ghirlanda G, et al. (2009) Peroxisome proliferator-activated receptors and angiogenesis. Nutr Metab Cardiovasc Dis 19(11): 751-759.

39. Oettgen P (2009) Functional redundancy of Ets1 and Ets2. Blood 114(5): 934-935.

40. Mahmoud, borlak Jürgen, Sleem Fathy (2011) Studies on hepatocell carcinoma due to miss use of preservatives Phd thesis, faculty of veterinary medicine. Mansoura university pp. 122 
ISSN: 2574-1241

DOI: 10.26717/BJSTR.2019.15.002661

Mahmoud M Elalfy. Biomed J Sci \& Tech Res

(C) This work is licensed under Creative BY Commons Attribution 4.0 License

Submission Link: https://biomedres.us/submit-manuscript.php

\begin{tabular}{ll}
\hline & Assets of Publishing with us \\
\hline RESEARCHES & - Global archiving of articles \\
\hline ISSN: $2574-1241$ & - Immediate, unrestricted online access \\
\end{tabular}

